\title{
Evolution and diversity of ram-suction feeding in damselfishes (Pomacentridae)
}

\author{
Damien Olivier $^{1} \cdot$ Laura Gajdzik $^{1} \cdot$ Eric Parmentier $^{1} \cdot$ Bruno Frédérich $^{1}$
}

Received: 17 October 2016 / Accepted: 13 January 2017 / Published online: 3 April 2017

(C) Gesellschaft für Biologische Systematik 2017

\begin{abstract}
The cerato-mandibular (c-md) ligament is a synapomorphy within Pomacentridae that creates a tight link between the lower jaws and the hyoid bars. However, this morphological trait has been secondarily lost in multiple lineages during evolution. A previous study revealed that the loss of this trait acted as a release of evolutionary constraints, leading to a cascade of morphological changes such elongated buccal jaws and a slender body. Ecomorphological interpretations suggested the loss of the c-md ligament has ultimately led to a new adaptive peak in zooplanktivory through an optimization of the ram feeding mode associated with a specialization in pelagic feeding. Here, we tested these hypotheses by comparing functional and diet diversity between damselfish species with and without the c-md ligament. Although species lacking the c-md ligament presented a conserved kinematic pattern resulting from high ram and low suction performances, our results did not support an optimization of the ram feeding mode. Indeed, some species with the c-md ligament showed the same or exceeded the ram performance of species without the c-md ligament. The species with the c-md ligament had a more diverse kinematic pattern exploring the entire ramsuction functional range in damselfishes. Finally, our results did not show any diet variations associated with the loss of the c-md ligament. Our study furthers the understanding of how a
\end{abstract}

Electronic supplementary material The online version of this article (doi:10.1007/s13127-017-0329-3) contains supplementary material, which is available to authorized users.

Damien Olivier

d.olivier.kreutz@gmail.com

1 Laboratoire de Morphologie Fonctionnelle et Evolutive, AFFISH Research Center, Institut de Chimie (B6C), Université de Liege, 4000 Liege, Belgium morphological trait has shaped, by its presence or absence, the ecomorpho-functional diversification of Pomacentridae.

Keywords Cerato-mandibular ligament $\cdot$ Evolutionary morphology $\cdot$ Specialization $\cdot$ Reef fishes $\cdot$ Zooplanktivory

\section{Introduction}

Evolutionary biologists have regularly investigated the form of organisms to understand the relationship between the morphology and the performance of lineages in their environment (Barel 1983; Koehl 1996; Wainwright and Reilly 1994). It can appear obvious, for example, the relationship between the elongate oral jaws of the labrid Epibulus insidiator and its extraordinary ability to protrude its jaws during feeding (Westneat and Wainwright 1989). However, it could be more complex, as with the suction index reflecting the ability of the fish to create a suction force on a prey (Carroll et al. 2004), and for which alternative combinations of its components produce the same mechanical property (Collar and Wainwright 2006).

Coral reef fishes display a dazzling array of buccal morphology (Wainwright and Bellwood 2002) which is assumed to underlie variation in their feeding ability or in the way they can use the same kind of prey. Within reef fishes, the damselfishes (Pomacentridae) represent a tremendous radiation with around 400 species (Eschmeyer et al. 2016; Frédérich and Parmentier 2016) grouped into three trophic guilds: (1) the pelagic feeders, or zooplanktivorous, that prey mainly upon planktonic copepods; (2) the benthic feeders, or grazers, that mainly feed on filamentous algae; and (3) an intermediate group including species that forage in both pelagic and benthic environments in variable proportions (e.g. planktonic and benthic copepods, small vagile invertebrates and filamentous algae; Frédérich et al. 2009; Frédérich et al. 
2016b; Gajdzik et al. 2016). During the last few years, different ecomorphological studies have conclusively highlighted relationships between these trophic guild and damselfish morphology (Aguilar-Medrano et al. 2011; Cooper and Westneat 2009; Cooper et al. 2016; Frédérich et al. 2006; Frédérich et al. 2008; Frédérich et al. 2016a).

The cerato-mandibular (c-md) ligament, linking the ceratohyal bar of the hyoid apparatus with the coronoid processes of the lower jaw, is a pomacentrid synapomorphy (Olivier et al. 2016a; Stiassny 1981). Previous kinematic studies revealed that this ligament allows rapid jaw closure (2 to $4 \mathrm{~ms}$ ) which is used to produce sound and communicate (Colleye and Parmentier 2012; Parmentier et al. 2007), to bite fixed prey (Olivier et al. 2015, 2016b) or to graze on small filamentous algae (Olivier et al. 2014). This ligament has been lost in several distantly related lineages, resulting in morphological modifications since species lacking this ligament have proportionally longer and thinner mandibles than species that have it (Frédérich et al. 2014). Moreover, this particular mandible shape is associated with a long ascending process of the premaxillary and an elongated body shape (Frédérich et al. 2014). In many fish groups, lengthened mandibles and long ascending process of the premaxillary are known to improve mouth protrusion (Hulsey et al. 2010; Waltzek and Wainwright 2003) which optimizes the capture of zooplanktonic prey (Coughlin and Strickler 1990; Liem 1993), whereas the slender body is related to a pelagic lifestyle (Webb 1984). Interestingly, the lack of the c-md ligament is also associated to a restricted diet, i.e., species with the c-md ligament are found in all trophic guilds of the family, whereas all species without it are zooplanktivorous (Frédérich et al. 2014). Based on these observations, it has been suggested that the loss of the c-md ligament may be associated to a cascade of morphological changes related to a new eco-functional pattern (Frédérich et al. 2014). However, this hypothesis still needs to be tested.

All damselfishes, irrespective of their trophic guild, can include planktonic prey in their diet (Frédérich et al. 2009). Fishes capturing elusive prey typically use a ram-suction feeding mode (Norton 1991). The ram-suction mode is made of two components, i.e., the ram distance and the suction distance. The ram distance corresponds to the movement of fish towards its prey and starts at the time the mouth opens. The suction distance is the passive movement of the prey towards the predator's mouth due to the suction force applied by the latter (Alexander 1969; Norton 1991; Norton and Brainerd 1993; Nyberg 1971). The ram distance is achieved through the protrusion distance (i.e., the forward movement of the upper jaw) and through the body-ram distance (i.e., the forward movement of the fish's body) (Wainwright et al. 2001). According to the hypothesis of Frédérich et al. (2014), the morphological variations associated with the loss of the cmd ligament in Pomacentridae could be related to an optimization of the ram feeding mode. An enhancement of the protrusion ability and a more streamlined body shape should improve the ram performance. An optimized ram strategy could be associated with a feeding on elusive prey that have a better capacity for detecting the predator and escaping the flow of water created by suction (Wainwright et al. 2001). Moreover, an elongated body could be associated with a more pelagic lifestyle and we can thus expect species lacking the cmd ligament to feed more on elusive planktonic prey than those with the c-md ligament.

In the present study, we test whether the species lacking the c-md ligament (1) differ in their performance in the capture of elusive prey and (2) show diet divergence from the species having the c-md ligament.

\section{Materials and methods}

\section{Specimens and husbandry}

Fifteen damselfish species from each trophic guild were studied (Fig. 1). The classification of each species in the different guilds was determined using stomach contents data if available (see "Diet data" below). In addition to the three trophic guilds, we created a fourth group including species lacking the c-md ligament. Stomach contents were not available for four species (i.e., Amblyglyphidodon flavilatus, Amphiprion frenatus, Dascyllus marginatus, and Pomacentrus trichourus) that were classified according to the data provided by Allen (1991).

Individuals were maintained in tanks of $\sim 1001$ with a 12L:12D photoperiod. Ten species came from marine ornamental trade and five were captured during field studies. Chromis chromis was captured in August 2011 in the Bay of Calvi (Corsica, France) and was studied at the "Station de Recherches Sous-marines et Océanographiques (STARESO)." Four species (A. flavilatus, Dascyllus aruanus, D. marginatus, and P. trichourus) were captured in February 2012 on a reef in Eilat (Israel) and studied at the "Interuniversity Institute for Marine Sciences (IUI)." Although less elusive than planktonic copepods (the main natural food of zooplanktivorous damselfishes; Frédérich et al. 2009), Artemia nauplii were used to study movements associated to feeding because they are very easy to produce and easily detectable on high-speed film. However, adults of Artemia sp. were used for two species A. flavilatus and A. frenatus because they were reluctant to feed on the nauplii stage.

\section{Kinematic and morphological data}

A high-speed video camera (RedLake MotionPro 2000, San Diego, USA; $1024 \times 1280$ pixels and Model NX4-S1, IDT, Tallahassee, USA; $640 \times 456$ pixels) was used to record feeding events in a $10-\mathrm{cm}$-width corridor where fishes were used 
Fig. 1 Phylogenetic relationships of the damselfishes studied for ram and suction performances. Circles at the tips indicated the different groups: no-

zooplanktivorous species with the cerato-mandibular (c-md) ligament, zooplanktivorous species with the c-md ligament, and zooplanktivorous without the cmd ligament. The shape of the head when the upper jaw is protruded is illustrated for each species; oral jaws are highlighted in green. The number of individuals used for both set of data (kinematic and morphological) and the mean of their head length are indicated

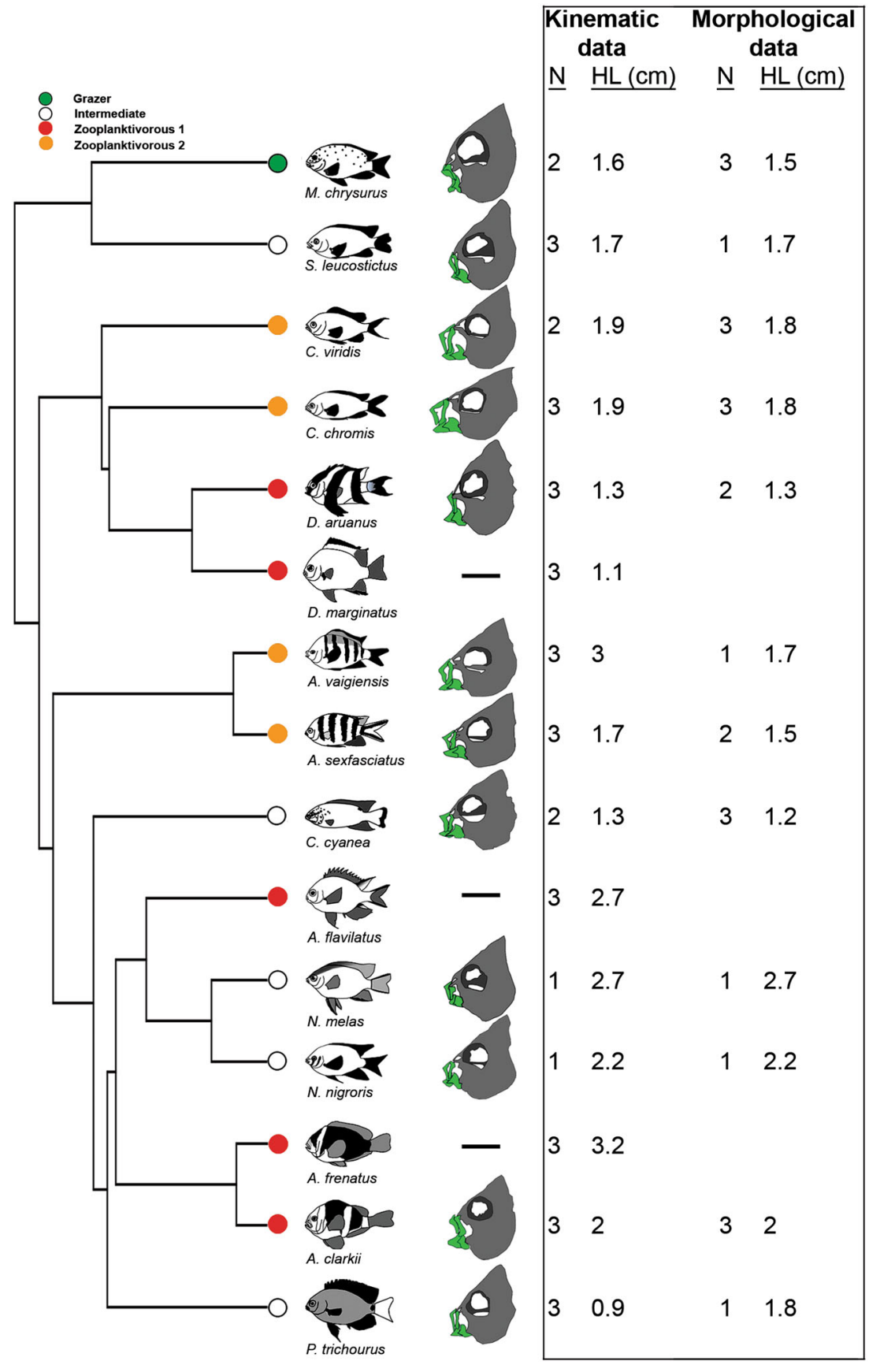

to being fed. Fish were offered one or a few items of prey at a time and were allowed to feed until satiated. Video sequences were considered only if the fish was in lateral view and if all the points of interest were clearly visible. A background grid was used to scale the fish movements. For the majority of the species, three individuals were studied (Fig. 1). From 6 to 15 video sequences per individual (average of 13) were analyzed (503 movies in total).

Each still image captured from film was digitized with the software Motion Studio 64 (IDT, Tallahassee, USA) and the $x, y$ coordinates of four landmarks were determined at the onset of each sequence: (1) the anterior tip of the premaxillary (upper jaw), (2) the anterior tip of the dentary (lower jaw), (3) the anterior margin of the eye's orbit, and (4) the estimated center of mass of the planktonic prey. Distances in the images were scaled by positioning a ruler on the background grid. The four landmarks were tracked through three discrete points in time: (1) the onset of mouth opening $\left(t_{0}\right)$, defined as the time at which the mouth was opened at $5 \%$ of its maximal gape, the gape being measured as the distance between the tips of upper and lower jaw; (2) the time of peak gape, defined as the time at which the straight-line distance between the tips of the upper and lower jaws first reached its maximum; and (3) the time of prey capture, defined as the frame preceding the one showing 
the prey crossing the virtual line between the tips of the upper and lower jaws. Changes in the position of the four landmarks were used to characterize predator and prey movements (variables explained in the next section). The strike duration (in millisecond, ms) was the period of time between $t_{0}$ and the capture of the prey.

The ram feeding was estimated by using several displacement variables (based on the method of Wainwright et al. 2001): (1) predator-prey distance, the distance between the predator and the prey at $t_{0} ;(2)$ body-ram distance, the distance moved towards the prey by the predator without including the contribution of upper jaw protrusion, i.e., the displacement of the anterior margin of the eye's orbit; and (3) protrusion distance, the displacement of the anterior tip of the premaxillary minus the displacement of the anterior margin of the eye's orbit.

The performance of suction feeding was investigated by using two different variables: (1) the suction distance, i.e., the movement of the prey induced by the suction force created by the predator, and (2) the suction index (SI). It has been recognized that suction distance might be a quite poor variable to assess suction performance (Wainwright et al. 2001). Indeed, the forces that determine the ability of the fish to draw prey into the mouth are inversely proportional with $d^{3}$, where $d$ is the distance of the prey from the center of the mouth (Muller et al. 1982). Because suction force decays exponentially with distance from the mouth aperture, little variation in the distance from which prey can be drawn in can be found (Wainwright et al. 2001). We, therefore, added the SI which is directly correlated with peak buccal pressure (Carroll et al. 2004; Holzman et al. 2008). The SI is a variable from a biomechanical model developed by Carroll et al. (2004) that correlates with maximal buccal pressure among closely related species as a function of the transmission of force from the epaxial muscles (proportional to the cross-sectional area of that muscle) to elevate the cranium and expand the buccal cavity (Fig. 2 and Online Resource 1).

\section{Diet data}

Diet information from stomach contents was collected in 61 damselfish species by compiling data from the literature and by dissections of fish stomachs in the laboratory (Online Resource 2). Fifteen species from French Polynesia were collected either on the fringing reef or on the outer reef slope at Moorea Island $\left(17.30^{\circ} \mathrm{S}, 149^{\circ} \mathrm{W}\right)$ during April-June 2014 (Online Resource 2). Fish were caught with clove oil or spearing at various depths from 1 to $25 \mathrm{~m}$. After their capture, fishes were brought to the surface and killed as quickly as possible by an overdose immersion in MS-222 (400 ppm). They were then placed on ice. Stomachs were opened and all dietary constituents were identified using a Leica DM 1000 binocular microscope. As the taxonomic level of prey

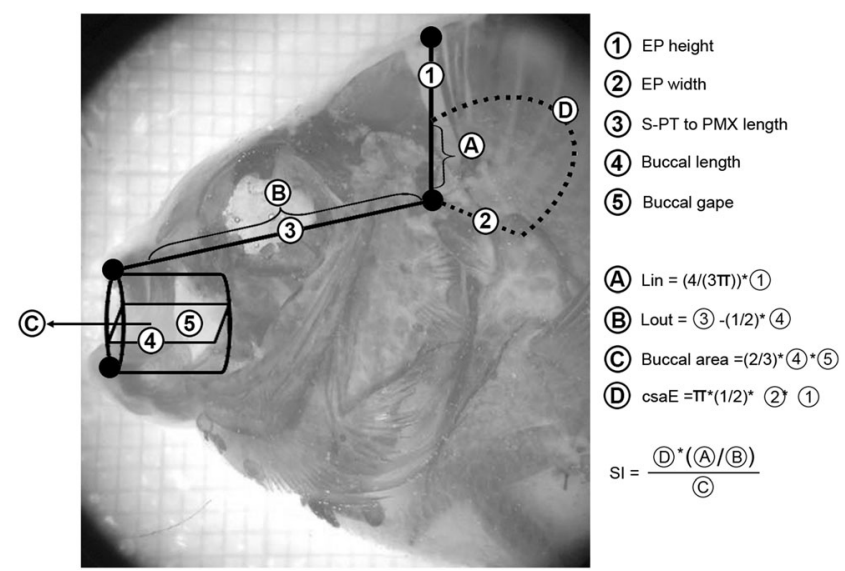

Fig. 2 A model of the morphological basis of the capacity to generate suction pressure in the buccal cavity (Carroll et al. 2004). The model allows one to relate morphological variation among fish individuals and species to relative capacity for generating suction pressure. EPAX $X_{c s a}$ cross-sectional area of the epaxial muscle, $E P$ epaxial muscle, $L_{i n}$ moment arm of the EP, $L_{\text {out }}$ moment arm of the buccal cavity, $P M X$ premaxillary, $S-P T$ joint between the supracleithrum and the postemporal of the pectoral girdle, $S I$ suction index. The cylinder represents the buccal cavity

identification varied largely among studies, preys were separated into two broad categories: free-living prey (mainly planktonic prey as small crustacean but also a few polychaetes, siphonophore, etc.) and fixed-living prey (almost exclusively filamentous algae, and small amounts of sponges and coral). If we found several times the same species in the dataset (literature + own data), we calculated a mean value for the species.

Based on the stomach contents, each species was assigned to one of the three trophic guilds following the methodology of Frédérich et al. (2009, 2016b; Online Resource 2). Species for which mobile prey represent $70 \%$ or more of the stomach content were categorized as "zooplanktivorous (or pelagic feeder)." Fish are "grazer (or benthic feeder)" when $70 \%$ or more of the stomach content was represented by immobile food items on the benthos. Species with less than $70 \%$ of items for both categories were classified as "intermediate" (Frédérich et al. 2009, 2016b, b). Under the hypothesis of a more pelagic lifestyle in species lacking the c-md ligament, we expected to find more mobile prey (mainly zooplankton) in those species than in the others.

By combining our stomach content analyses and data from literature, it has been possible to identify the proportions of calanoid copepods in the two groups of zooplanktivorous (13 zoo.1 and six zoo.2; Online Resource 3). Calanoid copepods are considered to be the most elusive invertebrate planktonic prey from the water column (Buskey and Hartline 2003; Lenz and Hartline 1999). Thus, a higher proportion of calanoid copepods would be expected in damselfishes lacking the c-md ligament under the hypothesis of ram feeding optimization. 


\section{Statistical analyses}

We used phylogenetic comparative methods to test hypotheses concerning functional divergence between the two morphological groups of damselfishes: species having the c-md ligament vs. species lacking it. Additionally, the same set of analyses was performed without considering evolutionary history in order to strengthen our interpretations. The molecular time-calibrated and multigene phylogeny of Pomacentridae from Frédérich et al. (2013) was pruned to match the species in the dataset and provided an estimate of the evolutionary relationships among taxa. All the studied species were found in that phylogeny, except for P. trichourus and A. flavilatus. Thus, the phyletic positions of Amblyglyphidodon ternatensis and Pomacentrus imitator were used for A. flavilatus and P. trichourus, respectively. Morphologically similar species were chosen as substitutes for A. flavilatus and P. trichourus. Moreover, here, only one species from the monophyletic genera Amblyglyphidodon and Pomacentrus were studied (Bernardi 2011; Santini and Cooper 2016). Thus, the topology of the pruned tree would not be altered by the choice of the substitutes. The time-calibrated phylogeny including the 15 studied species was used in the following phylogenetic comparative methods.

To investigate the ram-suction feeding mode, we first calculated the mean values for each individual of five kinematic variables (predator-prey distance, strike duration, body-ram distance, protrusion distance and suction distance) and one morphological variable (SI). One of our goals was to investigate a potential optimization of the ram feeding mode in species lacking the c-md ligament. Thus, we also considered the maximal values of both ram components (protrusion and body-ram) for each specimen; these variables were called the "maximum body-ram distance" and "maximum protrusion distance." Because there is body size variation among studied species, we accounted for size variation between specimens by applying a phylogenetic size correction of each displacement trait (i.e., predator-prey, body-ram, and protrusion distances) on head length and of suction distance on the buccal gape size (Revell 2009). Phylogenetic size correction was performed using the $\mathrm{R}$ codes from the function phyl.resid.intra recently developed by López-Fernández et al. (2014), allowing the inclusion of more than one individual per species.

We next used phylogeny-corrected ANOVAs to test divergence in the kinematic and morphological variables between species with and without the c-md ligament. We performed these comparisons using the $\mathrm{R}$ codes for the function phylANOVA.intra, also allowing the inclusion of more than one individual per species (López-Fernández et al. 2014). This function carries out an ANOVA, by comparing the results to a set of Brownian Motion (BM)-simulated values. Similarly a standard ANOVA, i.e., without including phylogenetic information, was performed with the function oneway.test in R (R Development Core Team 2016). As all the species without the c-md ligament are zooplanktivorous (Frédérich et al. 2014), we also ran all the analyses considering only zooplanktivorous species (zoo.1: c-md ligament present; zoo.2: c-md ligament absent), but we did not run these tests on SI values due to a too small sample size for the group zoo.1 (two species).

An optimization of the ram feeding mode could have led to highly similar kinematic patterns in lineages lacking the c-md ligament. We could test such a hypothesis by comparing the Brownian evolutionary rate parameter for kinematic traits between the two groups, and a lower rate in species lacking the c-md ligament would support a more conserved pattern in those species. However, our limited taxon sampling (four species lacking the c-md ligament) might have prevented the precise estimation of Brownian rate parameters. We therefore choose to quantify the diversity of kinematic patterns through the study of the ram-suction functional space. To obtain these, we run a phylogenetic principal component analysis (pPCA, function phylo.PCA of the phytools R-package; Revell 2012, phytools version 0.5 .0 ) on the species mean of four sizeadjusted variables (i.e., predator-prey distance, body-ram distance, protrusion distance, suction distance) and strike duration. We retained the two first axes of the pPCA which explain $82 \%$ of the total variation. The functional space for the two groups (with and without the c-md ligament) were calculated by measuring the total area (TA) contained by a convex hull which is the smallest polygon containing all values (Layman et al. 2007). As convex hull TA is very sensitive to extreme values, we also calculated the standard ellipse area (SEA) and more specifically standard ellipse corrected (SEAc) for small sample sizes for each group according to the method of Jackson et al. (2011). The standard ellipse for a set of bivariate data (in this case the first two axes of the pPCA) is calculated from its variance and covariance and reveals the core area that is insensitive to extremes values. The standard ellipse areas and convex hulls allow for graphical representation. To have statistical comparison, we used a Bayesian standard ellipse areas $\left(\mathrm{SEA}_{\mathrm{B}}\right)$ using Markov chain Monte Carlo simulation with $10^{4}$ iterations for each group using the package Stable Isotope Bayesian Ellipses (Jackson et al. 2011) in R (R Development Core Team 2016). The probability that there was a significant difference in the $\mathrm{SEA}_{\mathrm{B}}$ between the two groups (species with and without the c-md ligament) was assessed by calculating the proportion of iterations where the posterior estimate of ellipse area for one group was smaller than the other (Turner et al. 2010). The result was considered to be significant when $5 \%$ or less of the posterior estimated for one group were smaller than that of the other $(\alpha=0.05)$. The Bayesian ellipse technique and convex hull area calculations were performed using the SIAR package (Parnell et al. 2010) run in R 3.3.0 (R Development Core Team 2016). We also 
calculated these SEA and TA when only zooplanktivorous species were considered. Finally, we also produced a regular PCA on the mean values of the five kinematic variables (sizeadjusted if necessary) for each species by using the function prcomp in R (R Development Core Team 2016) and also calculated SEA and TA on the first two axes (explained 99\% of the total variation).

For the diet data, the proportion of free-living prey was transformed by the formula $p^{\prime}=\arcsin \sqrt{ }(p)$, where $p$ is the initial proportion value. ANOVAs and associated post hoc tests were performed with the function oneway.test in $\mathrm{R}(\mathrm{R}$ Development Core Team 2016) to detect divergence in the proportion of free-living prey among four groups: grazer, intermediate, zoo.1, and zoo.2. ANOVAs were also performed to test variation on the proportions of calanoid copepods between the two groups of zooplanktivorous species (zoo.1 and zoo.2).

\section{Results}

\section{Functional analysis}

Phylogeny-corrected ANOVAs showed functional divergences between species with and without the c-md ligament in their feeding patterns to capture elusive prey. The analyses without phylogenetic corrections confirmed these differences (Table 1).

Species without the c-md ligament attacked their prey from a farther distance and the strike duration was longer than in species with the c-md ligament (Fig. 3a, b and Table 1). To reach the prey, species without the c-md ligament relied on higher body-ram distance than other species (Table 1) although there is an overlap with Stegastes leucostictus (Fig. 3c). All these functional divergences differed significantly from that generated under a random walk, BM evolutionary process (Table 1). No difference between groups was found in the protrusion distance (Table 1 and Fig. 3d). The same result was obtained when maximal performances for body-ram distance were considered. The exception was that a marginal difference in maximal protrusion distances was found between groups (Table 1), but this variation could have occurred under BM evolution (Table 1). The highest body-ram performance was achieved by one species without the c-md ligament, but $S$. leucostictus showed higher values than the three other species also lacking a c-md ligament (Fig. 3e). The highest protrusion performance was achieved by A. flavilatus (Fig. 3f). Although A. sexfasciatus presented high value in general (mean value) in comparison with other species (Fig. 3c, e), the maximal body-ram performance of A. sexfasciatus was weak (Fig. 3c, e). Interestingly, a combination of high body-ram distance and high protrusion distance is only found in species without the c-md ligament (Fig. 3c-f). The suction distance and SI values are lower in species lacking the c-md ligament than in species with it (Fig. $3 \mathrm{~g}$, h and Table 1). The results considering only zooplanktivorous species showed the same patterns (Table 2).

With or without phylogenetic information, PCAs based on the first two principal components (Phylo-PCA, cumulative proportion of variance of $\mathrm{PC} 1$ and $\mathrm{PC} 2=82 \%$; $\mathrm{PCA}$, cumulative proportion of variance of $\mathrm{PC} 1$ and $\mathrm{PC} 2=99 \%$ ) showed that the feeding patterns used by species without the c-md ligament vary less than those performed by species with the c-md ligament (Fig. 4). The SEAs and the convex hull areas (TAs) of the species without the c-md ligament were smaller than those of species with the c-md ligament (Table 3). The Bayesian estimation of ram-suction functional space $\left(\mathrm{SEA}_{\mathrm{B}}\right)$ showed that more of $95 \%$ of the posterior ellipses for species without the c-md ligament were smaller than those of species with the c-md ligament, the difference in core ram-suction
Table 1 Comparison between species having and lacking the cerato-mandibular ligament

\begin{tabular}{|c|c|c|c|c|c|c|}
\hline & \multirow[b]{2}{*}{$d f$} & \multicolumn{3}{|c|}{ Phylogenetic corrections } & \multicolumn{2}{|c|}{$\begin{array}{l}\text { No phylogenetic } \\
\text { corrections }\end{array}$} \\
\hline & & $F$ value & $p$ value & $\begin{array}{l}p \text { value indicating difference } \\
\text { from } \mathrm{BM} \text { expectation }\end{array}$ & $F$ value & $p$ value \\
\hline Predator-prey distance & 1.36 & 8.43 & $<0.01$ & 0.01 & 8.43 & $<0.01$ \\
\hline Strike duration & 1.36 & 5.9 & 0.02 & 0.01 & 5.9 & 0.02 \\
\hline Body-ram distance & 1.36 & 8.44 & $<0.01$ & $<0.01$ & 8.44 & $<0.01$ \\
\hline Protrusion distance & 1.36 & 2.16 & 0.15 & 0.28 & 2.16 & 0.15 \\
\hline Max body-ram distance & 1.36 & 7.73 & $<0.01$ & 0.01 & 12.93 & $<0.01$ \\
\hline Max protrusion distance & 1.36 & 4.57 & 0.04 & 0.08 & 4.54 & 0.04 \\
\hline Suction distance & 1.36 & 17.5 & $<0.001$ & $<0.001$ & 17.5 & $<0.001$ \\
\hline Suction index & 1.22 & 16.57 & $<0.001$ & 0.01 & 16.57 & $<0.001$ \\
\hline
\end{tabular}

The results of ANOVAs with and without phylogenetic corrections are performed on individual's values. For the phylogenetic-corrected ANOVAs, $p$ values indicating divergence from an under random walk; Brownian process is also indicated. Significant results $(p<0.05)$ are bolded 
Fig. 3 Representation of the different parameters measured to assess ram and suction performances in damselfishes. Mean per species are represented; for variables of distance (A, C-G), the phylogeny size corrected residuals are used. The nozooplanktivorous species with the cerato-mandibular (c-md) ligament are represented in white, the zooplanktivorous species with the c-md ligament are in red, and the zooplanktivorous without the c$\mathrm{md}$ ligament are highlighted in orange a

Predator-Prey distance

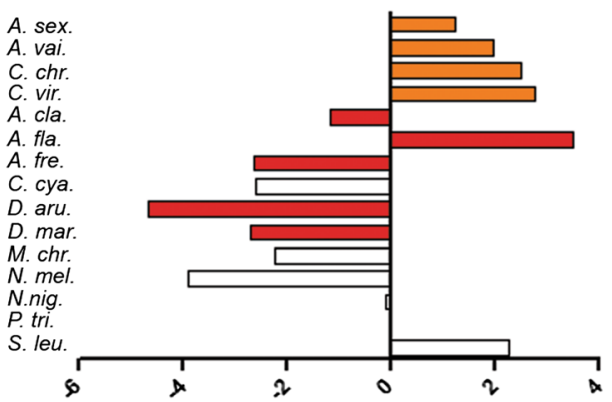

C Body-ram distance

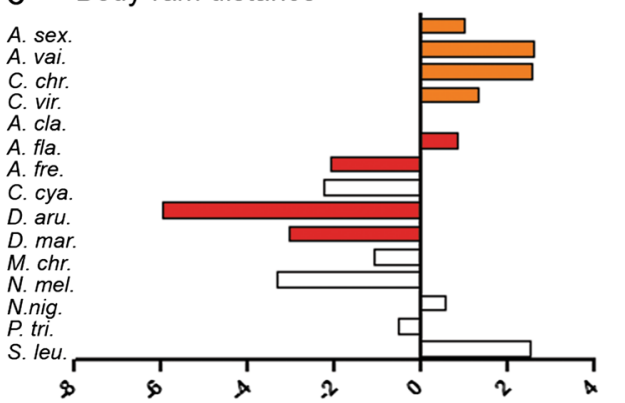

e Max Body-ram distance

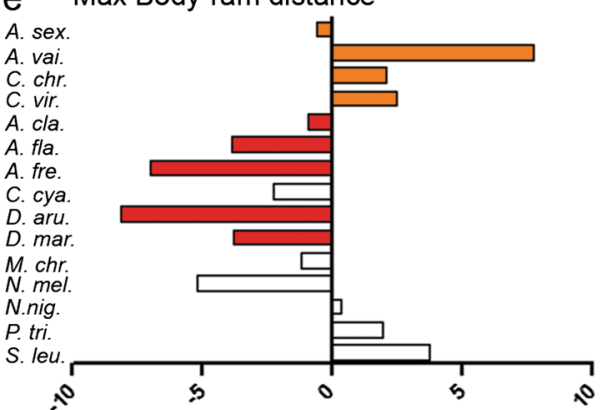

Suction distance

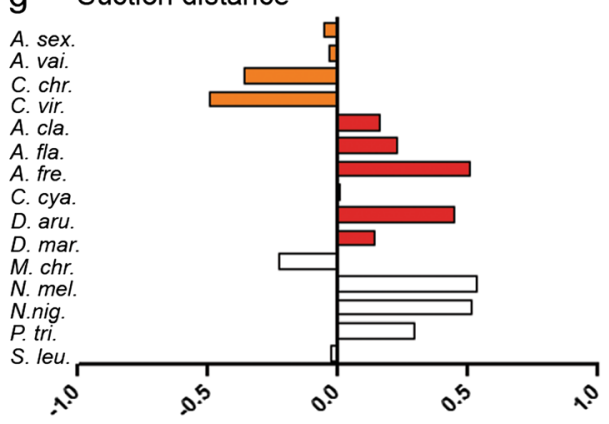

b Strike duration (ms)

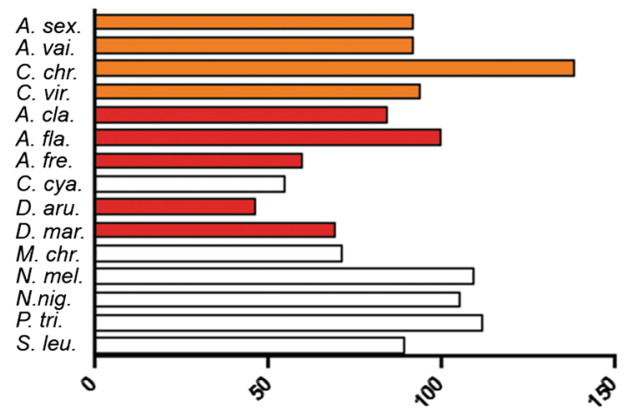

d Protrusion distance

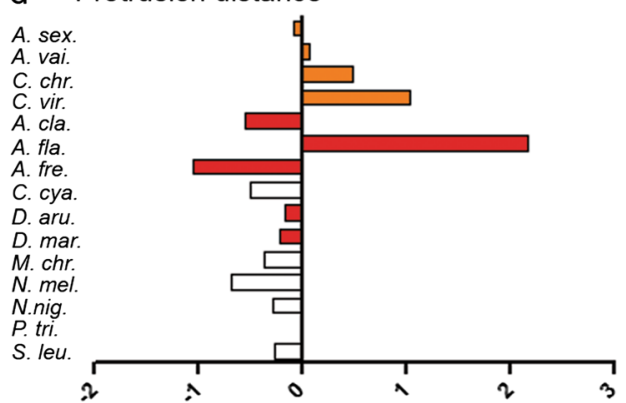

f Max Protrusion distance

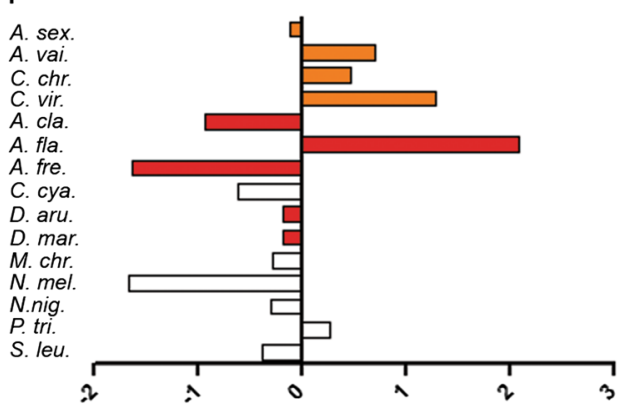

h Suction Index

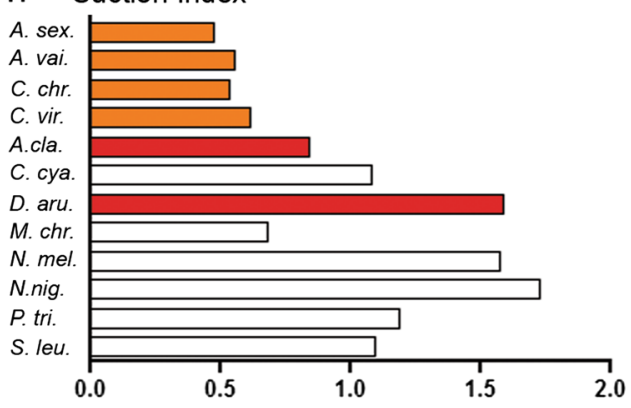

functional space between the two groups being therefore significant (Table 3). The same results were found with and without phylogenetic corrections and when only zooplanktivorous species were considered (Table 3).

\section{Diet analysis}

ANOVAs revealed differences among trophic groups in the proportion of free-living prey in their stomach contents $\left(F_{3}\right.$, $\left.{ }_{57}=139.1, p<0.001\right)$. The grazers feed on lower proportions of free-living prey $(13 \pm 10 \%)$ than the intermediate $(41 \pm 15 \%)$ and the two zooplanktivorous groups (zoo.1 = $87 \pm 10 \%$; zoo. $2=93 \pm 11 \%)$. The intermediate differed from all the other groups but no difference was found between the two groups of zooplanktivorous species (Table 4). The two groups of zooplanktivorous species did not differ in the proportion of calanoid copepods ingested (zoo.1 = $41 \pm 26 \%$; zoo. $2=55 \pm 18 \% ; F_{1,17}=1.7, p=0.21$ ). 
Table 2 Comparison between zooplanktivorous species having and lacking the cerato-mandibular ligament

\begin{tabular}{|c|c|c|c|c|c|c|}
\hline & \multirow[b]{2}{*}{$d f$} & \multicolumn{3}{|c|}{ Phylogenetic corrections } & \multicolumn{2}{|c|}{$\begin{array}{l}\text { No phylogenetic } \\
\text { corrections }\end{array}$} \\
\hline & & $F$ value & $p$ value & $\begin{array}{l}p \text { value indicating difference } \\
\text { from BM expectation }\end{array}$ & $F$ value & $p$ value \\
\hline Predator-prey distance & 1.24 & 7.52 & 0.011 & 0.013 & 7.49 & 0.011 \\
\hline Strike duration & 1.24 & 8.91 & $<0.01$ & $<0.01$ & 8.91 & $<0.01$ \\
\hline Body-ram distance & 1.24 & 9.58 & $<0.01$ & $<0.01$ & 9.44 & $<0.01$ \\
\hline Protrusion distance & 1.24 & 0.54 & 0.47 & 0.569 & 0.528 & 0.475 \\
\hline Max body-ram distance & 1.24 & 12.6 & $<0.01$ & $<0.01$ & 12.93 & $<0.01$ \\
\hline Max protrusion distance & 1.24 & 2.18 & 0.159 & 0.217 & 2.19 & 0.152 \\
\hline Suction distance & 1.24 & 22.44 & $<0.001$ & $<0.001$ & 21.5 & $<0.001$ \\
\hline
\end{tabular}

The results of ANOVAs with and without phylogenetic corrections are performed on individual's values. For the phylogenetic-corrected ANOVAs, $p$ values indicating divergence from an under random walk; Brownian process is also indicated. Significant results $(p<0.05)$ are bolded

\section{Discussion}

\section{Eco-functional comparison between Pomacentridae with and without the c-md ligament}

The hypothesis of this study suggested that the shape variations observed in damselfishes without the c-md

a

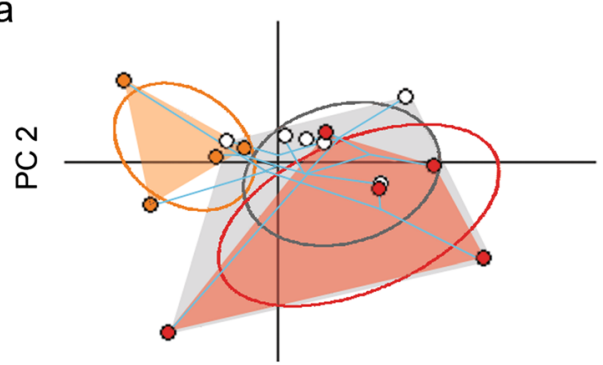

PC 1

b

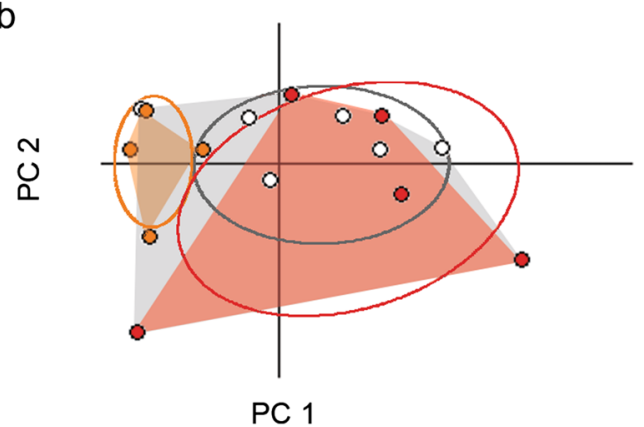

Fig. 4 Representation of the two main components of the Phylo-PCA (a) and PCA (b) made with five kinematic variables (predator-prey distance, body-ram distance, protrusion distance, suction distance, and strike duration). White dots correspond to no-zooplanktivorous species with the cerato-mandibular (c-md) ligament (no-zoo), red dots correspond to zooplanktivorous species with the c-md ligament (zoo.1), and orange dots correspond to zooplanktivorous species without the c-md ligament (zoo.2). For the phylo-PCA, phylogenetic relationships are highlighted in blue. The standard ellipses areas are represented by gray, red, and orange ellipses for no-zoo, zoo.1, and zoo.2 species, respectively. The convex hull areas are illustrated by gray, red and orange polygons for no-zoo, zoo.1, and zoo. 2 species, respectively ligament would be related to an optimization of the ram feeding mode (Frédérich et al. 2014). Generally speaking, damselfishes lacking the c-md ligament had a low suction performance; their suction distance was small and their SI had the lowest values among the studied species (Fig. 3h). However, counter to our simple expectations, there is not a total divergence in the ram performances between the two groups of damselfishes although predator-prey and bodyram distances were significantly higher in species without the c-md ligament than in species with it. Some species having the c-md ligament were able to produce or to exceed the ram performances of the species without the c-md ligament (Fig. 3). S. leucostictus presented one of the highest body-ram distance and A. flavilatus showed the highest protrusion distance (both when mean and maximal performances were considered). We have however to note that a combination of high jaw protrusion with high bodyram was only encountered in species without the c-md ligament (A. vaigiensis, C. chromis, and C. viridis). A. flavilatus showed a high protrusion performance but a low body-ram performance, the inverse was found for S. leucostictus. Despite this observation, the hypothesis of a ram feeding mode optimization would have only been strongly supported if species lacking the c-md ligament would have outperformed all species with the c-md ligament in both components of the ram feeding.

The species with the c-md ligament presented a more diverse ram-suction feeding pattern which embraces the full range of the functional space in damselfishes (Fig. 4). The following species illustrate such variations: D. aruanus performed a low body-ram and protrusion distances but an elevated suction distance; Microspathodon chrysurus had low values in both ram and suction distances; S. leucostictus performed a high body-ram distance but only a low protrusion and suction distances; and finally, A. flavilatus presented high value in protrusion and suction distance but only a low body-ram distance (Fig. 3). In contrast, species without the c-md ligament 
Table 3 Comparison of the standard ellipses areas (SEAs) and convex hull areas (TAs) between species with the c-md ligament (no-zoo and zoo.1) and species without the c-md ligament (zoo.2)

\begin{tabular}{llllll}
\hline & Phylo-PCA & & PCA \\
\cline { 2 - 3 } & SEA & & SEA & TA \\
\hline (No-zoo + zoo.1) vs. zoo.2 & Ratio $=1.6 ; p=\mathbf{0 . 0 3 7}$ & Ratio $=6.7$ & & Ratio $=3.9 ; p=\mathbf{0 . 0 1 4}$ & Ratio $=14.3$ \\
Zoo.1 vs. zoo.2 & Ratio $=2.8 ; p=\mathbf{0 . 0 3 1}$ & Ratio $=4.5$ & & Ratio $=7.4 ; p<\mathbf{0 . 0 1}$ & Ratio $=10.1$ \\
\hline
\end{tabular}

Significant results $p<0.05$ are bolded

showed a conserved kinematic pattern with moderate to high values in body-ram and protrusion distances and low suction distance (Fig. 3). Instead of a functional optimization, one way to capture elusive prey has been selected in species lacking the c-md ligament (Fig. 4).

Although zoo.2 (i.e., zooplanktivorous damselfishes without the c-md ligament) have a more elongated body, which could be linked to a more pelagic lifestyle, they do not feed on mobile prey (almost exclusively zooplankton) in higher proportion than zoo.1 (i.e., zooplanktivorous damselfishes having the c-md ligament). All studied zoo. 2 relied on ram performance and poorly on suction performance to capture elusive prey, which is not the case for zoo.1. We expected therefore to generally find more elusive prey (in this case calanoid copepods) in the stomach contents of zoo. 2 than in zoo.1, but no difference was found. It has been recognized that organisms can play the same role in a variety of ways (Koehl 1996; Mayr 1983; Stone 1995). For examples, several taxa of lizards utilize various techniques to dive into sand (Arnold 1995) or some species of snakes use different methods to capture whiptail lizards (Greene 1986). Bellwood et al. (2006) showed that some labrid fishes with different morphologies feed on similar prey and they stated that such a many-to-one relation between function and diet could facilitate diversification of other aspects in the ecology of organisms. They have illustrated that statement with crab feeding behavior. This feeding behavior did not restrict head shape or locomotor mode in labrids and therefore provided opportunities for behavioral specialization or mechanical specialization in other functional systems. Indeed, on one hand, some crab feeders are gracile and extensively modified for high mobility, and they dominate high wave energy locations. On the other hand, others are more robust and occupy lower energy locations

Table 4 Pair-wise comparisons of the free-living prey proportions found in the stomach contents of damselfish species following significant results in ANOVAS

\begin{tabular}{lllll}
\hline & Grazer & Intermediate & Zoo.1 & Zoo.2 \\
\hline Grazer (23) & 1 & & & \\
Intermediate (8) & $<0.001$ & 1 & & \\
Zoo.1 (22) & $<0.001$ & $<0.001$ & 1 & \\
Zoo.2 (8) & $<0.001$ & $<0.001$ & $>0.05$ & 1 \\
\hline
\end{tabular}

Number of species per groups is indicated in the brackets
(Bellwood and Wainwright 2001). Similarly, functional divergence to capture elusive prey in damselfish may be not related to what prey species the fish capture or to the degree of elusiveness of the prey but more to where the prey is generally encountered. Species without the c-md ligament could be cruiser or forager predators swimming in the water column searching for potential planktonic prey. Accordingly, a ram feeding mode relying less on the suction force should be well suited in this ecological context. On the other hand, zooplanktivorous species with the c-md ligament may occupy diverse habitats (e.g., close to benthos, among branching corals; Emery 1973) requiring different feeding strategies: a feeding relying on higher ram performances for foraging, a feeding relying more on suction performances for ambushing, or a combination of both of them. Future studies should explore further an ecological distinction between zooplanktivorous damselfishes with and without the c-md ligament.

\section{The theory of trait decoupling}

Trait decoupling, i.e., the uncoupling of previously coupled structures via the loss of a linkage, is one mechanism of releasing evolutionary constraints (Lauder 1981; Wainwright 2007). According to the theory of decoupling, it is expected that the level of morphological, functional, and ecological diversity would be the highest in lineages where a decoupling event has occurred (Emerson 1988; Lauder 1981; Schaefer and Lauder 1996; Tsuboi et al. 2015). Morphological disparity is higher in loricarioid lineages with observed anatomical decoupling than in lineages without (Schaefer and Lauder 1996). The functional diversity increased with functional decoupling of the adductor mandibulae in Tetraodontiforms (Friel and Wainwright 1999). It has also been largely argued that the functional decoupling between food collecting and preparation resulted in the emergence of numerous diverse collecting mechanisms in cichlids (Hulsey et al. 2006; Liem 1973). The results of the present study could be quite unexpected under the hypotheses of trait decoupling, suggesting that the case of damselfishes is quite different from the preceding examples. The c-md ligament may have acted as an evolutionary constraint on the shape of the mandible (Frédérich et al. 2014). In this sense, the decoupling, via the loss of this trait, has indeed permitted formerly integrated 
structures to diversify. This new shape of mandible is associated with a cascade of other morphological changes such as a long ascending process of the premaxillary and an elongated body shape (Frédérich et al. 2014). Thus, on one hand, the evolutionary loss of the c-md ligament promotes the diversification of Pomacentridae because it allows the emergence of new phenotypes (Frédérich et al. 2014). On the other hand, the decoupling event has led indirectly to a decrease in the variability of functional and ecological diversity because the species without the c-md ligament are all zooplanktivorous and were found to perform a strong conserved kinematic pattern to capture elusive prey. Another unpredicted consequence of trait decoupling has occurred in the marine angelfishes (Pomacanthidae). In this family, a novel joint between the angular and the dentary of the lower jaws makes these bones more mobile (Konow and Bellwood 2005), but this increase of mobility has been associated with a remarkably conserved kinematic pattern of biting among distantly related lineages (Konow and Bellwood 2011). The examples of Pomacentridae and Pomacanthidae illustrate that an evolutionary outcome of anatomical decoupling may not ultimately lead to a burst of eco-functional diversification.

\section{Conclusion}

In Pomacentridae, the c-md ligament appears to be an important morphological trait having shaped their evolution (Olivier et al. 2016a, b). Its loss promotes diversification by allowing species without this trait to colonize a new morphological space. However, the loss of the c-md ligament is associated with a decrease in the trophic diversity and in the ram-suction functional variability: all the species without the c-md ligament are zooplanktivorous and occupy a limited range of the ram-suction functional space of the Pomacentridae. The species with the c-md ligament represent the different trophic guilds of the family and explore the full ram-suction functional space. Contrary to our expectation, the functional variation between zooplanktivorous species with and without the c-md ligament does not seem to be related to any diet variation and future studies should be carried out to shed light on this manyto-one relationship. Our study provides new insights on the influence of a morphological trait on the diversification of the Pomacentridae and reinforces the statement that the relationship between morphological, functional, and ecological diversity is difficult to disentangle.

Acknowledgements We thank the two anonymous reviewers for their helpful comments. We thank Dr. Roi Holzman for making us welcome at the Interuniversity Institute for Marine Sciences, Eilat (IUI). DO was a $\mathrm{PhD}$ student of FRIA. BF is a postdoctoral fellow at the Belgian Science Policy (BELSPO). LG is a research fellow of F.R.S-F.N.R.S. This research was supported by the FRFC grants from the F.R.S.-FNRS (no.
2.4.535.10) and by the Association of European Marine Biological Laboratories (ASSEMBLE).

\section{References}

Aguilar-Medrano, R., Frédérich, B., De Luna, E., \& Balart, E. F. (2011). Patterns of morphological evolution of the cephalic region in damselfishes (Perciformes: Pomacentridae) of the Eastern Pacific. Biological Journal of the Linnean Society, 102(3), 593-613. doi:10. 1111/j.1095-8312.2010.01586.x.

Alexander, R. M. (1969). Mechanics of the feeding action of a cyprinid fish. Journal of Zoology (London), 159, 1-15.

Allen, G. R. (1991). Damselfishes of the world. Melle: Aquarium Systems.

Arnold, E. N. (1995). Identifying the effects of history on adaptation: origins of different sand-diving techniques in lizards. Journal of Zoology (London), 235, 351-388.

Barel, C. D. N. (1983). Towards a constructional morphology of cichlid fishes (Teleostei: Perciformes). Netherlands Journal of Zoology, 33, 357-424.

Bellwood, D. R., \& Wainwright, P. C. (2001). Locomotion in labrid fishes: implications for habitat use and cross-shelf biogeography on the Great Barrier Reef. Coral Reefs, 20(2), 139-150. doi:10. 1007/s003380100156.

Bellwood, D. R., Wainwright, P. C., Fulton, C. J., \& Hoey, A. S. (2006). Functional versatility supports coral reef biodiversity. Proceedings of the Royal Society B, 273, 101-107. doi:10.1098/rspb.2005.3276.

Bernardi, G. (2011). Monophyletic origin of brood care in damselfishes. Molecular Phylogenetics and Evolution, 59, 245-248.

Buskey, E. J., \& Hartline, D. K. (2003). High-speed video analysis of the escape responses of the copepod Acartia tonsa to Shadows. The Biological Bulletin, 204, 28-37.

Carroll, A. M., Wainwright, P. C., Huskey, S. H., Collar, D. C., \& Turingan, R. G. (2004). Morphology predicts suction feeding performance in centrarchid fishes. Journal of Experimental Biology, 207, 3873-3881. doi:10.1242/jeb.01227.

Collar, D. C., \& Wainwright, P. C. (2006). Discordance between morphological and mechanical diversity in the feeding mechanism of centrarchid fishes. Evolution, 60(12), 2575-2584. doi:10.1111/j. 0014-3820.2006.tb01891.x.

Colleye, O., \& Parmentier, E. (2012). Overview on the diversity of sounds produced by Clownfishes ( Pomacentridae ): importance of acoustic signals in their peculiar way of life. PLOS ONE, 7(11). doi: 10.1371/journal.pone.0049179.

Cooper, W. J., \& Westneat, M. W. (2009). Form and function of damselfish skulls: rapid and repeated evolution into a limited number of trophic niches. BMC Evolutionary Biology, 9(24), 1-17. doi:10. 1186/1471-2148-9-24.

Cooper, W. J., Carter, C. B., Conith, A. J., Rice, A. N., \& Westneat, M. W. (2016). The evolution of jaw protrusion mechanics has been tightly coupled to bentho-pelagic divergence in damselfishes (Pomacentridae). Journal of Experimental Biology. doi:10.1242/ jeb. 143115.

Coughlin, D. J., \& Strickler, J. R. (1990). Zooplankton capture by a coral reef fish: an adaptive response to evasive prey. Environmental Biology of Fishes, 29, 35-42.

Emerson, S. B. (1988). Testing for historical patterns of change: a case study with frog pectoral girdles. Paleobiology, 14, 174-186.

Emery, A. R. (1973). Comparative ecology and functional osteology of fourteen species of damselfish (Pisces: Pomacentridae) at Alligator Reef, Florida Keys. Bulletin of Marine Science, 23(3), 649-770. 
Eschmeyer, W. N., Fricke, R., \& van der Laan, R. (2016). Catalog of fishes: genera, species, references (http://research.calacademy.org/ research/ichthyology/catalog/fishcatmain.asp).

Frédérich, B., \& Parmentier, E. (2016). Biology of damselfishes. Boca Raton: CRC Press.

Frédérich, B., Parmentier, E., \& Vandewalle, P. (2006). A preliminary study of development of the buccal apparatus in Pomacentridae (Teleostei, Perciformes). Animal Biology, 56(3), 351-372. doi:10. 1163/157075606778441831.

Frédérich, B., Adriaens, D., \& Vandewalle, P. (2008). Ontogenetic shape changes in Pomacentridae (Teleostei, Perciformes) and their relationships with feeding strategies: a geometric morphometric approach. Biological Journal of the Linnean Society, 95(1), 92-105. doi:10.1111/j.1095-8312.2008.01003.x.

Frédérich, B., Fabri, G., Lepoint, G., Vandewalle, P., \& Parmentier, E. (2009). Trophic niches of thirteen damselfishes (Pomacentridae) at the Grand Récif of Toliara, Madagascar. Ichthyological Research, 56(1), 10-17. doi:10.1007/s10228-008-0053-2.

Frédérich, B., Sorenson, L., Santini, F., Slater, G. J., \& Alfaro, M. E. (2013). Iterative ecological radiation and convergence during the evolutionary history of damselfishes (Pomacentridae). The American Naturalist, 181(1), 94-113. doi:10.1086/668599.

Frédérich, B., Olivier, D., Litsios, G., Alfaro, M. E., \& Parmentier, E. (2014). Trait decoupling promotes evolutionary diversification of the trophic and acoustic system of damselfishes. Proceedings of the Royal Society B, 281, 20141047. doi:10.1098/rspb.2014.1047.

Frédérich, B., Cooper, W. J., \& Aguilar-Medrano, R. (2016a). Ecomorphology and iterative ecological radiation of damselfishes. In B. Frédérich \& E. Parmentier (Eds.), Biology of damselfishes (pp. 183-203). Boca Raton: CRC press.

Frédérich, B., Olivier, D., Gajdzik, L., \& Parmentier, E. (2016b). Trophic ecology of damselfishes. In B. Frédérich \& E. Parmentier (Eds.), Biology of damselfishes (pp. 153-167). Boca Raton: CRC press.

Friel, J. P., \& Wainwright, P. C. (1999). Evolution of complexity in motor patterns and jaw musculature of tetraodontiform fishes. Journal of Experimental Biology, 202, 867-880.

Gajdzik, L., Parmentier, E., Sturaro, N., \& Frédérich, B. (2016). Trophic specializations of damselfishes are tightly associated with reef habitats and social behaviours. Marine Biology, 163(12), 249.

Greene, H. W. (1986). Diet and arboreality in the emerald monitor, Varanus prasinus, with comments on the study of adaptation. Fieldiana Zoology, 31, 1-12.

Holzman, R., Collar, D. C., Day, S. W., Bishop, K. L., \& Wainwright, P. C. (2008). Scaling of suction-induced flows in bluegill: morphological and kinematic predictors for the ontogeny of feeding performance. Journal of Experimental Biology, 211, 2658-2668. doi:10. 1242/jeb.018853.

Hulsey, C. D., García de León, F. J., \& Rodiles-Hernández, R. (2006). Micro- and macroevolutionary decoupling of cichlid jaws: a test of Liem's key innovation hypothesis. Evolution, 60(10), 2096-2109. doi:10.1111/j.0014-3820.2006.tb01847.x.

Hulsey, C. D., Hollingsworth, P. R., \& Holzman, R. (2010). Co-evolution of the premaxilla and jaw protrusion in cichlid fishes (Heroine: Cichlidae). Biological Journal of the Linnean Society, 100(3), 619-629. doi:10.1111/j.1095-8312.2010.01468.x.

Jackson, A. L., Inger, R., Parnell, A. C., \& Bearhop, S. (2011). Comparing isotopic niche widths among and within communities: SIBER - Stable Isotope Bayesian Ellipses in R. Journal of Animal Ecology, 80(3), 595-602. doi:10.1111/j.1365-2656.2011.01806.x.

Koehl, M. A. R. (1996). When does morphology matter? Annual Review of Ecology and Systematics, 27(1), 501-542. doi:10.1146/annurev. ecolsys.27.1.501.

Konow, N., \& Bellwood, D. R. (2005). Prey-capture in Pomacanthus semicirculatus (Teleostei, Pomacanthidae): functional implications of intramandibular joints in marine angelfishes. Journal of Experimental Biology, 208, 1421-1433. doi:10.1242/jeb.01552.
Konow, N., \& Bellwood, D. R. (2011). Evolution of high trophic diversity based on limited functional disparity in the feeding apparatus of marine angelfishes (f. Pomacanthidae). PLoS ONE, 6(9). doi:10. 1371/journal.pone. 0024113

Lauder, G. V. (1981). Form and function: structural analysis in evolutionary morphology. Paleobiology, 7(4), 430-442.

Layman, C. A., Arrington, D. A., Monta, C. G., \& Post, D. M. (2007). Can stable isotope ratios provide for community-wide measures of trophic structure? Ecology, 88(1), 42-48.

Lenz, P. H., \& Hartline, D. K. (1999). Reaction times and force production during escape behaviour of a calanoid copepod, Undinula vulgaris. Marine Biology, 133, 249-258. doi:10.1007/ s002270050464.

Liem, K. F. (1973). Evolutionary strategies and morphological innovations: cichlid pharyngeal jaws. Systematic Zoology, 22, 425-441.

Liem, K. F. (1993). In B. H. J. Hanken (Ed.), Ecomorphology of the teleostean skull. The skull: functional and evolutionary mechanisms. Chicago: The University of Chicago Press.

López-Fernández, H., Arbour, J., Willis, S., Watkins, C., Honeycutt, R. L., \& Winemiller, K. O. (2014). Morphology and efficiency of a specialized foraging behavior, sediment sifting, in neotropical cichlid fishes. PloS One, 9(3), e89832. doi:10.1371/journal.pone. 0089832 .

Mayr, E. (1983). How to carry out the adaptationist program? The American Naturalist, 121(3), 324-334.

Muller, M., Osse, J., \& Verhagen, J. (1982). A quantitative hydrodynamical model of suction feeding in fish. Journal of Theoretical Biology, $45,49-79$.

Norton, S. F. (1991). Capture success and diet of cottid fishes: the role of predator morphology and attack kinematics. Ecology, 72(5), 1807. doi: $10.2307 / 1940980$.

Norton, S. F., \& Brainerd, E. L. (1993). Convergence in the feeding mechanics of ecomorphologically similar species in the Centrarchidae and Cichlidae. Journal of Experimental Biology, 176, 11-29.

Nyberg, D. W. (1971). Prey capture in the largemouth bass. The American Midland Naturalist, 86, 128-144.

Olivier, D., Frédérich, B., Spanopoulos-Zarco, M., Balart, E. F., \& Parmentier, E. (2014). The cerato-mandibular ligament: a key functional trait for grazing in damselfishes (Pomacentridae). Frontiers in Zoology, 11(1), 63. doi:10.1186/s12983-014-0063-z.

Olivier, D., Frédérich, B., Herrel, A., \& Parmentier, E. (2015). A morphological novelty for feeding and sound production in the yellowtail clownfish. Journal of Experimental Zoology Part A, 323(4), 227-238. doi:10.1002/jez.1907.

Olivier, D., Frédérich, B., \& Parmentier, E. (2016a). Cerato-mandibular ligament: a key trait in damselfishes? In B. Frédérich \& E. Parmentier (Eds.), Biology of damselfishes (pp. 291-309). Boca Raton: CRC press.

Olivier, D., Parmentier, E., \& Frédérich, B. (2016b). Insight into biting diversity to capture benthic prey in damselfishes (Pomacentridae). Zoologischer Anzeiger, 264, 47-55. doi:10.1016/j.jcz.2016.07.006.

Parmentier, E., Colleye, O., Fine, M. L., Frédérich, B., Vandewalle, P., \& Herrel, A. (2007). Sound production in the clownfish Amphiprion clarkii. Science, 316(5827), 1006. doi:10.1126/science.1139753.

Parnell, A. C., Inger, R., Bearhop, S., \& Jackson, A. L. (2010). Source partitioning using stable isotopes: coping with too much variation. PloS One, 5(3), 1-5. doi:10.1371/journal.pone.0009672.

R Development Core Team, R (2016). R: a language and environment for statistical computing. Vienna, Austria: R Foundation for Statistical Computing. See http://R-project.org/.

Revell, L. J. (2009). Size-correction and principal components for interspecific comparative studies. Evolution, 63, 3258-3268.

Revell, L. J. (2012). phytools: an R package for phylogenetic comparative biology (and other things). Methods in Ecology and Evolution, 3, 217-223. 
Santini, F., \& Cooper, W. J. (2016). A revised damselfish taxonomy with a description of the tribe Microspathodontini (Giant damselfishes). In B. Frédérich \& E. Parmentier (Eds.), Biology of damselfishes (pp. 13-30). Boca Raton: CRC press.

Schaefer, S. A., \& Lauder, G. V. (1996). Testing historical hypotheses of morphological change: biomechanical decoupling in loricarioid catfishes. Evolution, 50(4), 1661-1675. doi:10.2307/2410902.

Stiassny, M. L. J. (1981). The phyletic status of he family Cichlidae (Pisces, Perciformes): a comparative anatomical investigation. Netherlands Journal of Zoology, 31(2), 275-314. doi:10.1163/ $002829681 X 00013$.

Stone, R. (1995). Taking a new look at life through a functional lens. Science (New York, N.Y.), 269, 316-317. doi:10.1126/science.269.5222.316

Tsuboi, M., Gonzalez-voyer, A., \& Kolm, N. (2015). Functional coupling constrains craniofacial diversification in Lake Tanganyika cichlids. Biology Letters, 11, 20141053. doi:10.1098/rsbl.2014.1053.

Turner, T. F., Collyer, M. L., Krabbenhoft, T. J., Ecology, S., August, N., Turner, T. F., et al. (2010). A general hypothesis-testing framework for stable isotope ratios in ecological studies. Ecology, 91(8), 22272233.
Wainwright, P. C. (2007). Functional versus morphological diversity in macroevolution. Annual Review of Ecology and Systematics, 38, 381-401. doi:10.1146/annurev.ecolsys.38.091206.095706.

Wainwright, P. C., \& Bellwood, D. R. (2002). Ecomorphology of feeding in coral reef fishes. In P. F. Sale (Ed.), Coral Reef Fishes: dynamics and diversity in a complex ecosystem (pp. 33-55). San Diego: Academic Press.

Wainwright, P. C., \& Reilly, S. M. (1994). Ecological morphology: integrative organismal biology. (P. C. Wainwright \& S. M. Reilly, Eds.). University of Chicago Press.

Wainwright, P. C., Ferry-Graham, L. A., Waltzek, T. B., Carroll, A. M., Hulsey, C. D., \& Grubich, J. R. (2001). Evaluating the use of ram and suction during prey capture by cichlid fishes. Journal of Experimental Biology, 204, 3039-3051.

Waltzek, T. B., \& Wainwright, P. C. (2003). Functional morphology of extreme jaw protrusion in Neotropical cichlids. Journal of Morphology, 257(1), 96-106. doi:10.1002/jmor.10111.

Webb, P. W. (1984). Body form, locomotion and foraging in aquatic vertebrates. American Zoologist, 24, 107-120.

Westneat, M. W., \& Wainwright, P. C. (1989). Feeding mechanism of Epibulus insidiator (Labridae; Telesotei): evolution of a novel functional system. Journal of Morphology, 205, 269-275. 